\title{
ANALYSIS OF FEASIBILITY TO ASSESS MICROSTRUCTURE OF GAS TURBINE BLADES BY MEANS OF THE THERMOGRAPHIC METHOD
}

\section{ANALIZA MOŻLIWOŚCI OCENY STANU MIKROSTRUKTURY LOPATEK TURBINY GAZOWEJ METODĄ TERMOGRAFICZNĄ}

\author{
Artur Kułaszka, Józef Błachnio, Lukasz Kornas
}

\author{
Air Force Institute of Technology \\ ul. Księcia Bolesława 6, 01-494 Warszawa 46, Poland, \\ e-mail: artur.kulaszka@itwl.pl,jozef.blachnio@itwl.pl, lukasz.kornas@itwl.pl,
}

\begin{abstract}
Operation of avionic turbine engines is always associated with possibility of various defects that may happen to turbine components, in particular to its blades. The most frequent reason for defects is overheating of the blade material but the thermal fatigue also occurs quite often. The most efficient examination method that provides plenty of information about structure of the investigated material of turbine blades is metallography but it is a destructive testing technology, so that the turbine no longer can be used after such investigation. This paper deals with methods of non-destructive tests that are currently in use and applicability of such methods to unbiased and trustworthy computer-aided diagnostics aimed to find out how the blade microstructure status varies in time. Results of initial examination of gas turbine blades are presented whereas the tests with use of the non-invasive thermographic method were carried out in order to assess condition of the blade material after the turbines had been subjected to the effect of high temperatures. Subsequently, the obtained results were successfully validated by means of the metallographic method. Eventually the conclusion could be made that the thermographic method makes it possible to achieve comprehensive and trustworthy information how microstructure of the blade materials is altered during the aircraft operation.
\end{abstract}

Keywords: gas turbine, blade, thermography, microstructure, diagnostics

Streszczenie: $W$ procesie eksploatacji lotniczych silników turbinowych wystepuja różnego rodzaju uszkodzenia elementów turbin, a zwlaszcza ich topatek. Najczestsza ich przyczyna jest przegrzanie materiatu, a także zmęczenie cieplne topatek. Mimo, iz badania metoda metalograficzna dostarczaja informacje o strukturze badanego materiatu topatek turbiny, to w rezultacie sa to badania niszczace uniemozliwiajace ich dalsze wykorzystanie. Wartykule omówiono stosowane obecnie metody badań nieniszczacych oraz możliwości ich wykorzystania do obiektywnego diagnozowania zmian stanu mikrostruktury. topatek turbin. Przedstawiono wyniki wstepnych badań topatek turbiny gazowej poddanych wysokiej temperaturze z zastosowania nieinwazyjnej metody termograficznej do oceny stanu ich mikrostruktury. Wyniki te z powodzeniem zweryfikowano badaniami metoda. metalograficzna. Stwierdzono, ze metoda termograficzna umożliwia uzyskanie dobrej wiarygodności oceny stanu zmian mikrostruktury topatek.

Stowa kluczowe: turbina gazowa, topatka, termografia, mikrostruktura, diagnozowanie 


\section{Introduction}

Numerous advantages of gas turbines, such as their capability to provide high power at rather modest dimensions and low own weight, pretty high efficiency of the energy conversion process (30-45\%) [1], simple design, easy operation and maintenance under wide range of climatic conditions (in particular at low ambient temperatures) as well as satisfying reliability - all these benefits served as the reason for wide application of gas turbines in power engineering machinery and in avionic engines. On the other hand, gas turbines have also substantial drawbacks, for instance high working temperatures of some their parts and high rotation speed of their rotors. It leads to the need to manufacture these parts of very expensive alloys that are creep-resistant at high temperatures as well as to design very sophisticated shapes of blades, which substantially handicaps the manufacturing process of them.

Efficiency of gas turbines that actually are rotating machines that convert enthalpy of the working agent into some amount of mechanical work, depends significantly on the temperature of exhaust gases. Over the several recent years that temperature was increased by $280 \mathrm{~K}$, which enabled to improve general efficiency of turbines and to increase their power factor.

Increase of the turbine efficiency is conducive to the rise of the engine traction (power) and to savings on unit fuel consumption by the motor. Obviously, the reverse relationship is also valid.

Reliability and durability of avionic turbine and turbojet engines substantially depend on the gas turbine performance as the turbine blades are subjected to heavy thermal and mechanical loads in the aggressive atmosphere of exhaust gases. Currently, the working temperature of turbine blades ranges from $1120 \mathrm{~K}$ to $1500 \mathrm{~K}$ and depends on materials the blades are made of and special measures, such as cooling or coating of turbine blades with special protective films. Simultaneously, rotation speed of avionic turbine engines can be even as high as above $100000 \mathrm{rpm}$ depending on the engine design and its target application.

It is why operators of avionic motors have to cope with the task to use the best available diagnostic techniques and expert knowledge in order to early detect and appropriately account for symptoms of possible hazards so that the repairs and remedy actions are taken at the most beneficial moment in terms of cost-effectiveness, minimization of loss and prevention from breakdowns. In addition, very expensive technologies that are necessary for 
repairs of avionic engines compel the engineers to search for new nondestructive methods that are suitable to assess technical condition of the equipment, during both scheduled maintenance and further validation when components of turbines are repaired.

\section{Reasons for thermal deterioration of gas turbine blades during operation of the equipment and types of defects}

The process of gas turbine operation induces origination of various defects that strike components of gas turbines. Among these components the turbine blades are exposed to the most frequent failures, hence technical condition of these parts in of crucial importance for reliability and lifetime of the entire turbine and the subassembly where it is installed. Analysis of literature references $[2,3]$ shows that only a small percent of turbine blades defects is caused by low quality of the blade material as well as design or technological faults (Fig. 1) due to the fact that the blades undergo very strict quality control during both the manufacturing and assembly processes.

The past experience of the Air Force Institute of Technology gained from the completed research studies [4] shows that most of thermal defects in gas turbines is caused by improper settings or adjustments of the engine or poor quality of the combusted fuel.

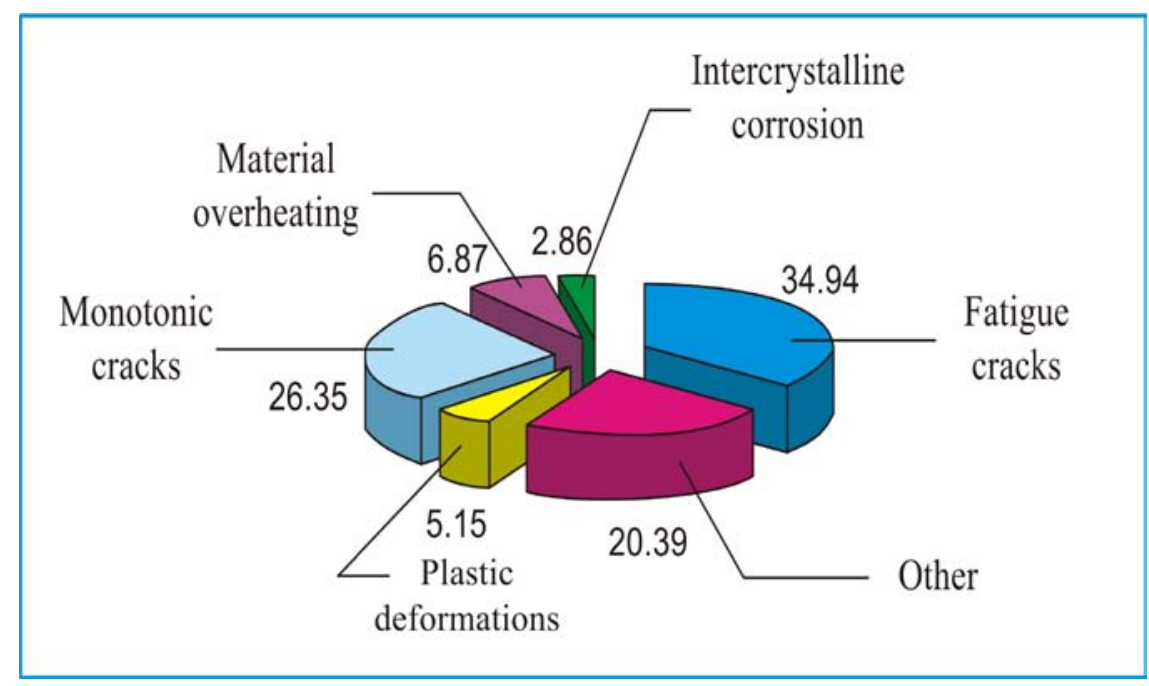

Fig. 1. Reasons for defects that may happen to turbine avionic engines during the process of their operation (in percents) [2] 
Incorrect fuel pressure, worsening of its chemical and physical properties as well as contaminations of any type or incorrect positioning of the injector in the flame tube head - all these reasons lead to build-up of carbon deposits (Fig. 2) $[4,5]$. It results in disturbances in organization of the combustion process, and therefore, to alterations in distribution of the temperature field and drawbacks in cooling of individual components within the hot part of the engine (Fig. 3).

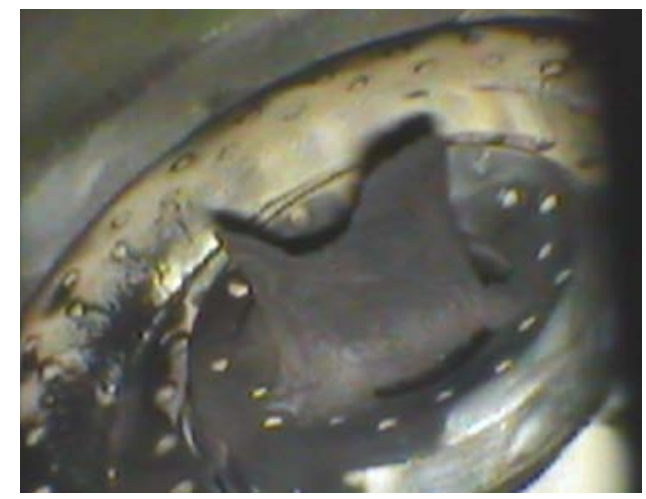

Fig. 2. Carbon deposit on the injector of a turbojet engine [4]

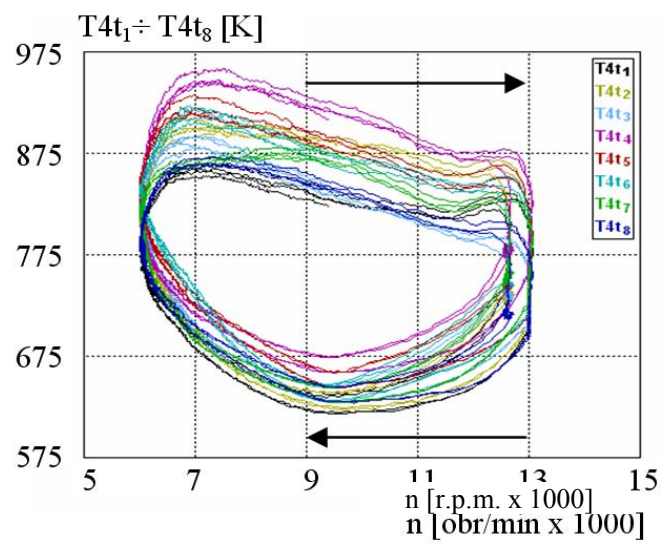

Fig. 3. Example of a momentary temperature distribution downstream the turbine measured by means of thermocouples [6]

Such circumstances consequently result in overheating of both the combustion chamber and the turbine blades. Similarly, any damage to protective coatings (Fig. 4) that cover turbine blades co-act with the effect exerted by the high temperature and aggressive composition of combustion gases, which finally brings about to overheating of the blade body.

Further operation of the engine at presence of such defects may be a reason for consequential destruction of the turbine blades and is hazardous to safety of the engine operation. 


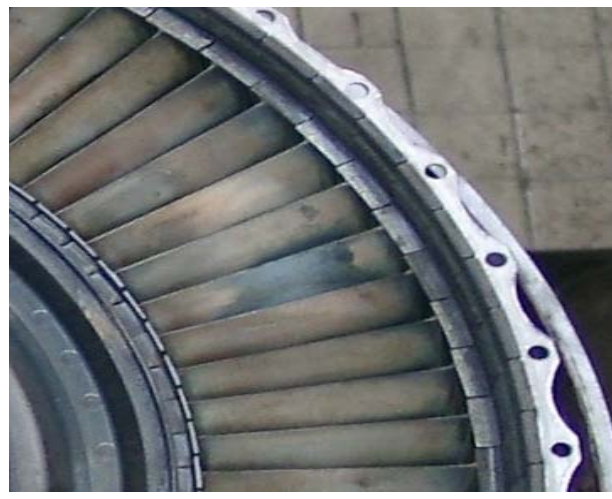

a

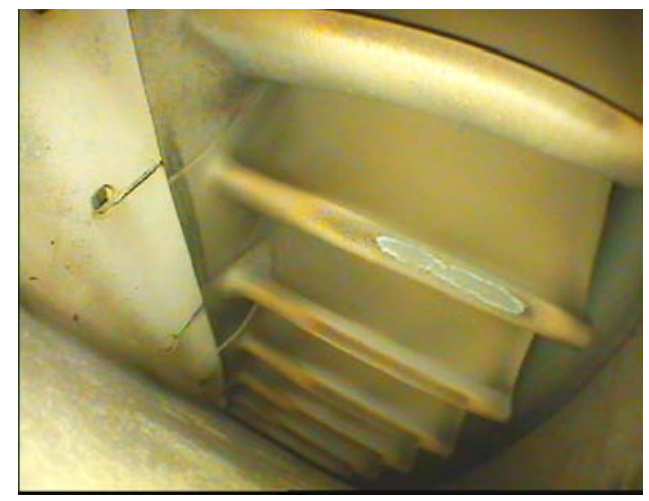

b

Fig. 4. Types of thermal damage to blades of a gas turbine: a) overheating of the blade body that is manifested by alteration of the surface colour to bleu and glaucous, b) local melting of the protective coating [4]

\section{Diagnostic feasibility of technical condition demonstrated by turbine blades}

Defects that may strike gas turbines of avionic engines are really hazardous as they may lead to total breakdown of the engine with consequential aircraft catastrophe. It is why designer of avionic engines have been forced to develop a number of Non-Destructive Testing methods, where visual inspection is the most popular one. It is the method that makes it possible to examine even hard accessible components of engines (e.g. with use of a videoscope) in a non-invasive manner, with sufficient dependability, easily and at low expense. Most of manufacturers that deliver new turbine engines adapted their designs to enable endoscopic inspections by providing borescope orifices on the entire engine body to allow access to the engine interior and to examine the whole path of exhaust gases during the engine lifetime, where particular attention is paid to turbine blades. Such a solution makes it possible to detect any discontinuities of materials, first and foremost those discontinuities that are dangerous as they extend over surfaces of the components, regardless to the defect size and its geometrical shape. Nowadays visual inspections are usually performed with videoscopes that have supplanted endoscopes (borescopes and fibroscopes) that widely used before. Analyzers of video images (video analyzers) represent another type of equipment that automatically compare 3D images acquired during the examination procedures with reference images stored in the computer 
memory. Unfortunately, none of the above methods enable to unambiguously judge how much structures of the turbine blades are altered due to overheating of the blade material. The assessment of the overheating status is carried out by an operator who is crafty with the visual methods and uses a videoscope to compare the obtained images with reference ones. Such a diagnosis is burdened by a human factor so in the long run the operator's decisions are validated by execution of destructive metallographic tests.

The maintenance and repair procedures for turbine blades commonly use various NDT methods to assess condition of turbine blades: visual inspection, penetration, ultrasonic, X-ray, thermographic and tightness tests as well as the eddy current method. Under the provision of limited dependability the mentioned NDT methods enable:

- detection of discontinuities in materials (flaw detection),

- assessment of material properties (structuroscopic analyses),

- determination of size and dimensions of objects and measurements of their thickness (metrology)

Currently, none fully dependable and trustworthy method is known and used in Poland so that it would enable diagnostics all the blades inside gas turbines, both during operation and in overhauls.

\section{Innovative methods applicable to diagnostic of technical condition demonstrated by blades of gas turbines}

Over the few recent years researches have developed and implemented several innovative NDT methods based on the following principles:

- analysis of images that present surfaces of the object illuminated with white light - the RGB method,

- detection of infrared radiation emitted by the examined object - the thermographic method,

- recording of X-ray images - the method of computer tomography,

The RGB method

The RGB method for visual inspections is based on componential colours (R-red, G - green and B - blue) and benefits from the relationship between physical and chemical properties of examined surfaces and wave characteristics of light reflected by such surfaces. These relationships are decisive for angle properties of both falling and reflected light beams and about absorption of individual wavelengths within the spectrum of the electromagnetic radiation [7]. 
The assessment of the blade condition is based on analysis of colour images that are representative for the examined surfaces and is associated with the criterion of the investigated material (alteration of blade shapes and increase in the number of hits for the reinforcing phase of $\gamma^{\prime}$ ), i.e. deterioration of the high-temperature creep resistance and heat resistance after exceeding of the threshold temperature of the exhaust gas, whilst the threshold temperature of the exhaust gas is specific for each individual material. Based on the nomogram that presents relationship of changes in surface temperature (RGB colours, grey scale) as a function of the blade heating the researcher is capable to determine alterations in the alloy microstructure.

The images are recorded by means of the CCD matrix and then analyzed with use of specialized application software that takes advantage of sophisticated algorithms for image processing and is meant to compare the current images with the already recorded reference patterns in order to provide qualitative assessment of the surface under test. It was the method that was applied to assess condition of gas turbine blades made of the ŻS$6 \mathrm{~K}$ alloy (Fig. 5).

With use of $\mathrm{m}$-files developed in the MatLab software environment one can extract and amplify properties of the images recorded for the examined surfaces. These properties are demonstrated as histograms that represent distribution of intensities for individual components of colours as well as parameters that are determined for the matrix of events.

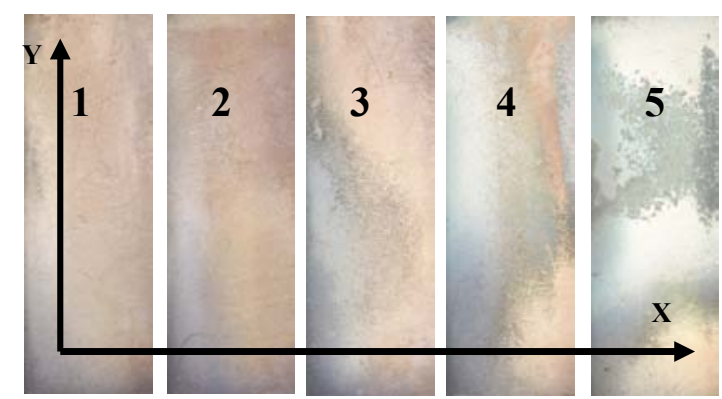

Fig. 5. Images for surfaces of gas turbine blades made of the ŻS-6K alloy, ordered according to the criterion of the increasing degree of the material overheating [7]

Specific parameters, such as location of the maximum amplitude (the intensity value for RGB colours), averaged valued for the entire images (intensity values that are added together in each row and then divided by the number of rows) as well as the value for the maximum amplitude are 
calculated for the examined blade section. The histogram brings quantitative information on intensity of the recorded image and each histogram is represented as a single vector where the vector length corresponds to the number of the intensity steps. To achieve homogeneity of values represented by various histograms the term of normalized histogram is introduced, where the individual values are divided by the total number of pixels. Fig. 6 presents examples for variations of the position value for the maximum amplitude of the image intensities for various technical conditions of blades from Fig. 5.

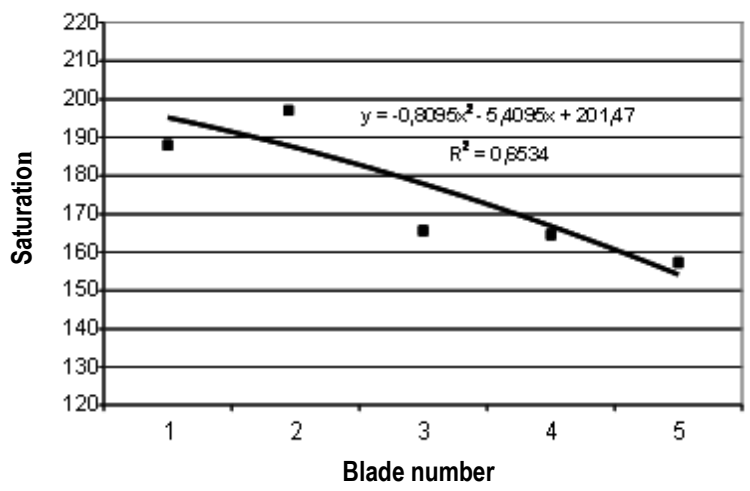

Fig. 6. Variations of the position value for the maximum amplitude of the image intensities for various technical conditions of blades from Fig. 5 (in grey scale)

Satisfactory results can be achieved when the ring-wedge detector is used for the analysis. The ring-wedge detector is a circle-shaped structure that is made up of two parts, where the first part is represented by concentrically deployed rings and the second part comprises wedges with the common vertex in the geometrical centre of the detector. Each of these areas is considered as a surface light-detector that transforms intensity of the falling light into the signal that is proportional to that intensity of the falling light.

The hologram produced by the computer software $(\mathrm{KGH})$ presents the shape that is identical to the ring-wedge detector and is also made up of ring and wedge areas. Therefore the computer hologram (KGH) acts as the extractor of features from images that are presented in the domain of frequencies. Results of the analysis of images for surfaces of the turbine blades from Fig. 5 are shown in Fig. 7. Values for wedges and rings overlapped to overheated blades no 4 and no 5 are clearly different from the remaining ones. 
Monochromatic image (grey scale)

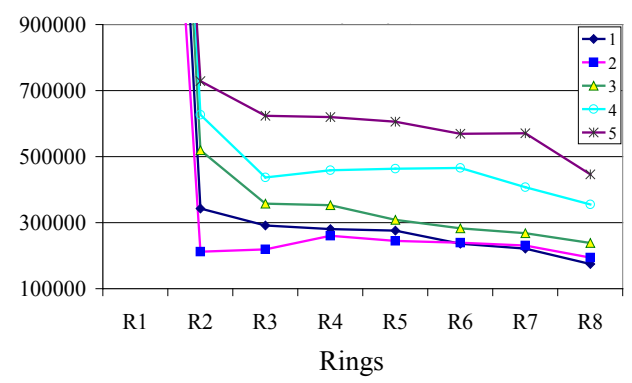

Monochromatic image (grey scale)

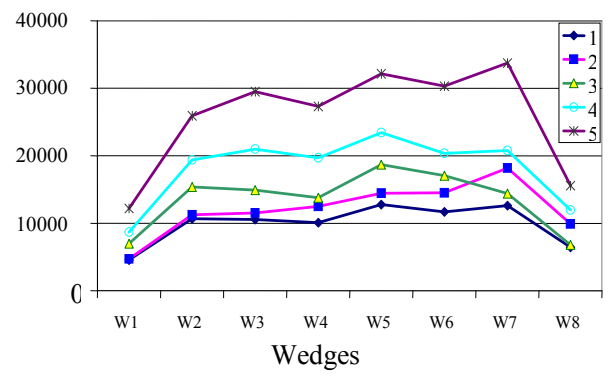

Fig. 7. Values of rings and wedges in the grey scale for individual deterioration degrees of wedges from Fig. 5 [8]

Every instrument that is equipped with a CCD matrix may produce RGB components with slightly different spectral characteristics which, in turns, is associated with some restrictions to the range of parameters, e.g. intensity of colours. Therefore not only is it necessary to develop algorithms for a specific type of equipment but also standard patterns are necessary for each individual types of surfaces, e.g. blades of individual turbines.

\section{The thermographic method}

Similarly to any other NDT techniques, the method of infrared thermography that is based on detection and recording of infrared radiation can be split into its passive and active variations. Diagnostics of gas turbines with application of the passive thermography consists in recording of images that present distribution of temperatures at the turbine exhaust [9]. When the turbine is working with no technical problems one can record reference thermographic images and then, during regular maintenance and operational tests the acquired thermograms are compared with the reference ones. Detection of even slightest irregularities is a symptom that one must seek for the core reason for such deviations. This approach makes it possible to detect such flaws (e.g. turbine erosion, defects of blades, incorrect operation of the combustion chamber) that are very hard detectable when other non-destructive testing techniques are applied [10].

The recent years have brought growth of the interest to apply the active infrared thermography to detect flaws in the surface adjacent layer of materials. The essence of such examination consists in investigation how the specific material responds to stimulation by means of an external pulse of heat. When some amount of thermal energy is delivered to the material surface, e.g. as a pulse of heat, the material surface begins to change rapidly 
right after termination of the pulse. Due to thermal diffusion the thermal front starts moving towards deeper layers of the material. Presence of areas that differ in thermal properties (containing flaws) from the ones without such flaws results in variation of the diffusion velocity. Thus, monitoring of the temperature field on the material sample that is being cooled down enables location of flaws. Differentiation of the stimulation method makes it possible to distinguish several types of the active thermography, namely the pulsed thermography, the lock-in thermography with modulated heating and the pulsed phase thermography [11].

The pulsed thermography is deemed as a rather simple variation of the active thermography and consists in determination and analysis of the temperature distribution on the examined surface when the surface is being spontaneously cooled down after having been uniformly heated by means of a thermal pulse (Fig. 8). For the one-dimensional model and homogenous material it is possible to formulate the equation that describes temperature variation when the surface is being cooled down after heating with a short thermal pulse [12]:

$$
T(t)-T(0) \sim Q \alpha^{-\frac{1}{2}} t^{-\frac{1}{2}}
$$

where: $Q$ stands for energy of the thermal pulse per each surface unit, $t$ is the current time how long the surface is being cooled down, $T(0)$ temperature at the selected point or on the area of the heated surface, just after termination of the thermal pulse and $T(t)$ - temperature at any moment of the spontaneous cooling process.

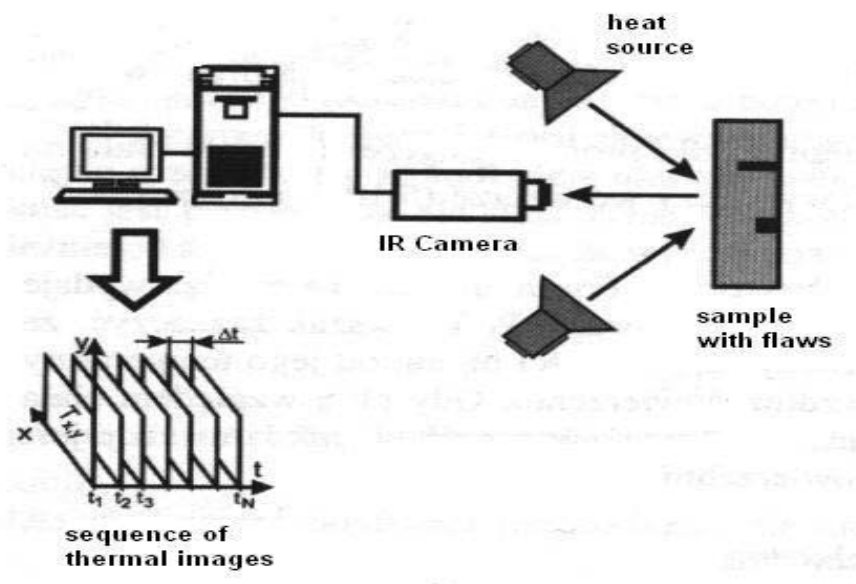

Fig. 8 Application diagram for the pulsed thermography [13] 


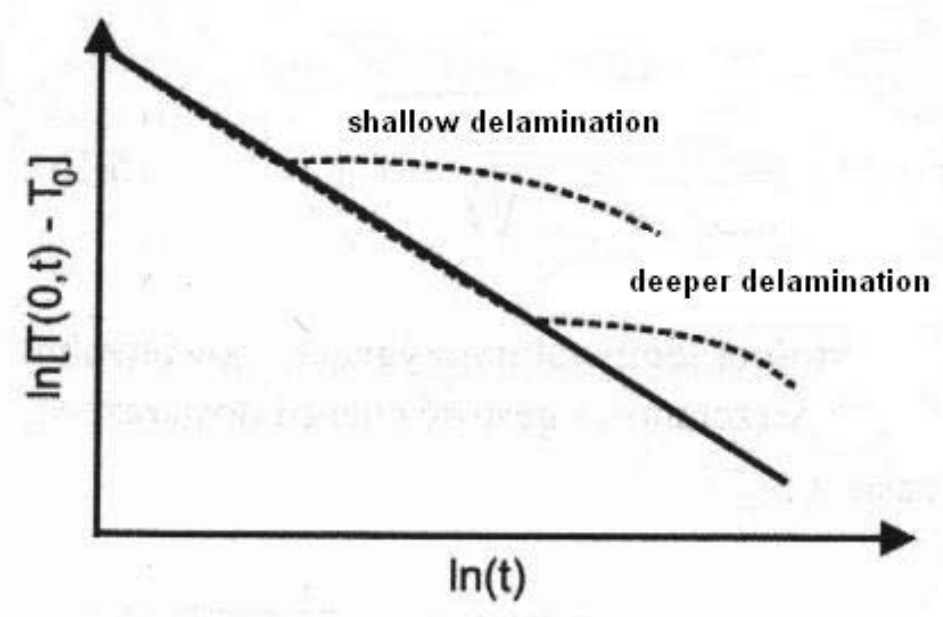

Fig. 9 Detection of delamination by means of the pulsed thermography [13]

When any flaws occur in the examined material the diffusion rates are reduced which leads to the image that the temperature of the surface area above the flaw is different from the one that is free of defects beneath - the interrelationship amends its nature. Various defects, for instance delamination of coating or plies can be revealed by plotting a graph (Fig. 9). For homogenous materials the graph presents a straight line with its slope of 1/2. Obviously, this method, similarly to other one, has its limitations, as it enables to detect flaws only in surface-adjacent layers of materials due to the fact that temperature contrast rapidly fades out with the depth of penetration.

\section{Results from preliminary research studies on feasibility to apply the thermographic analysis to assess microstructure of the turbine blades}

The ITWL has initiated research studies intended to find out whether the thermographic method is suitable to assess alterations in the microstructures of gas turbine blades. For that purposes the workbench called „Echo Therm System" from Thermal Wave Imaging was used. The examination involved samples from new blades, made of the alloy EI - 867 WD and subjected to thermal ageing in an oven at various temperatures. Consequently, clear alterations in the relationship between parameters of the thermal response from sample materials was obtained (Fig. 10). 

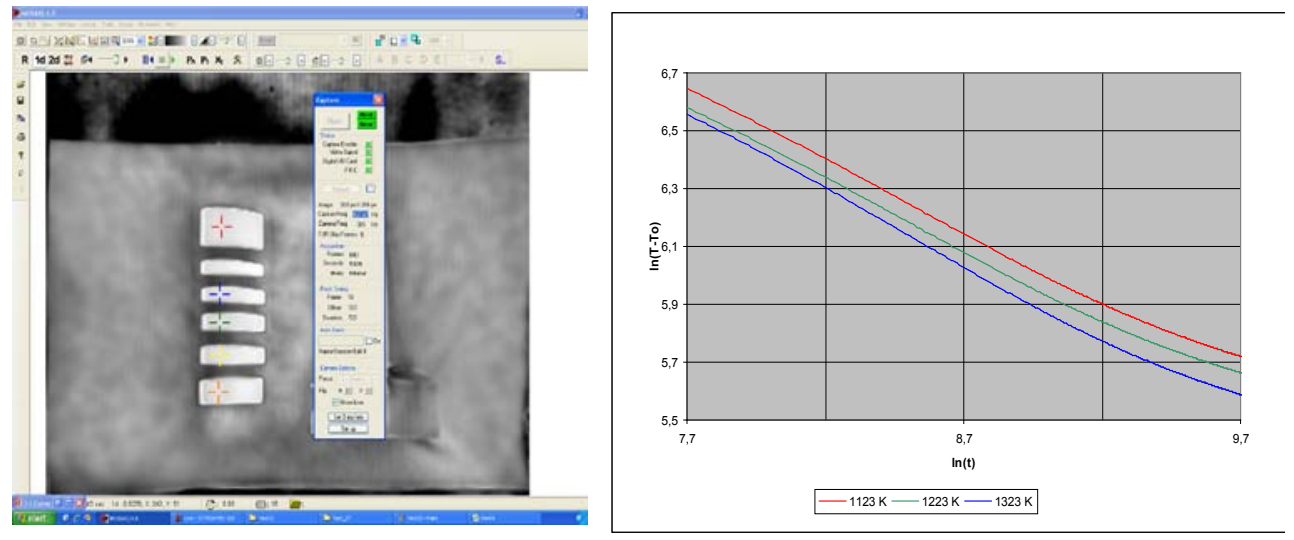

Fig. 10. Appearance of samples examined with use of the Echo Therm System workbench along with the graph that presents a response to a thermal pulse applied to samples after ageing at temperatures of $1123 \mathrm{~K}, 1223 \mathrm{~K}$ and $1323 \mathrm{~K}$

After completion of metallographic examinations the assessment was carried out how the microstructure of samples had been altered, particularly for variations of the reinforcing phase $\gamma^{\prime}-\mathrm{Ni}_{3}(\mathrm{Al}, \mathrm{Ti})$. Results of these examinations are presented in Fig. 11 as a nomogram.

The relationship between the thermal response of the sample material, represented as the value of $\ln (T-T o)$ and the average number of hits for the $\gamma^{\prime}$ phase enables to assess technical condition of the sample material. This relationship, in conjunction with the permissible alterations to the microstructure, serves as a basis to judge whether the sample material is suitable or not for further service.

High temperature affects both to variations of the aluminium coating and to alterations to the structure of the $\gamma^{\prime}$ phase. The investigated microstructure of the surface-adjacent layer reflects changes in the EI - $867 \mathrm{WD}$ alloy and confirms overheating of the alloy structure after the blade samples had been aged at temperatures that ranged from only $1223 \mathrm{~K}$ (Fig. 12 and 13). 


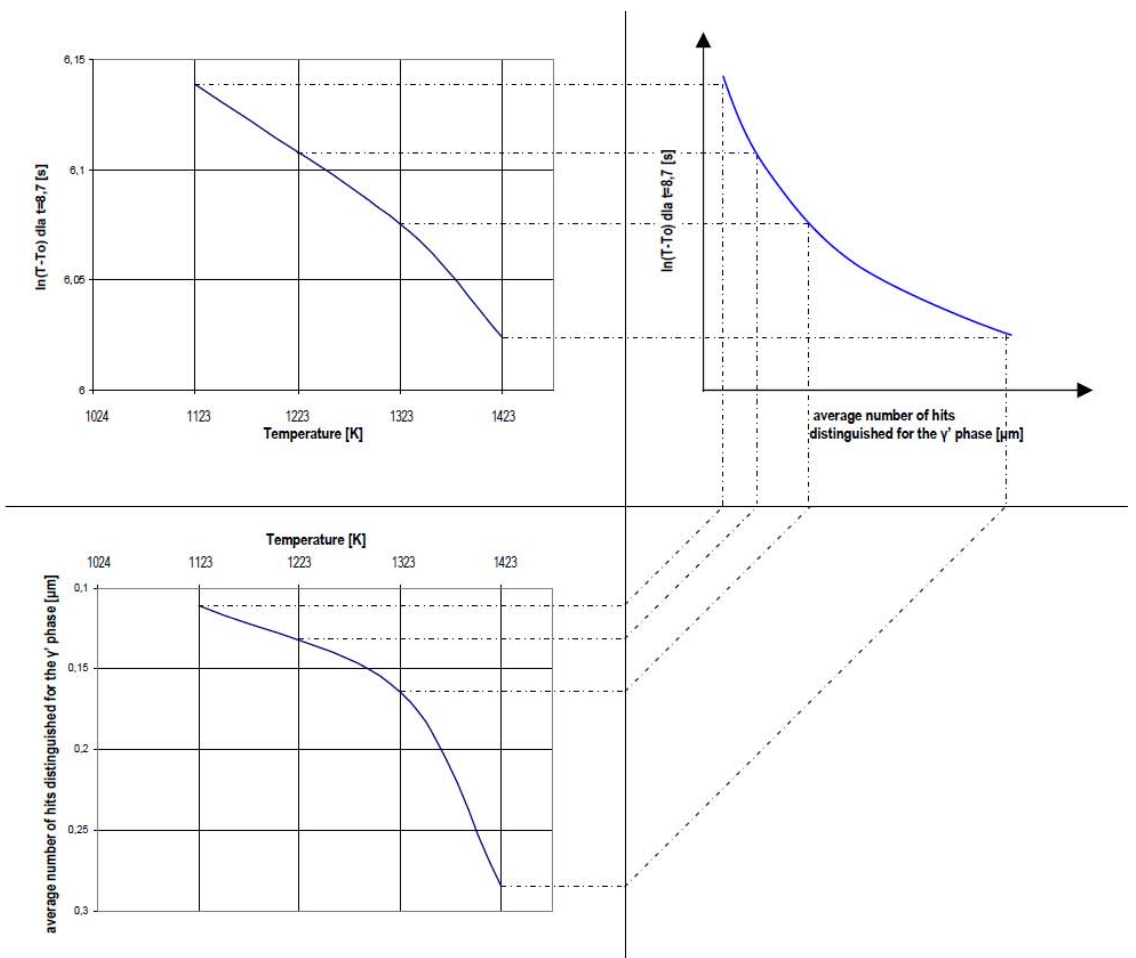

Fig. 11. The nomogram to assess microstructures of samples taken from a gas turbine made of the EI - 867 WD alloy plotted on the basis of the relationship between variation of the parameter $\ln (T-T o)$ for the signal attributable to the thermographic method and variation in the number of hits for the $\gamma^{\prime}$ phase at various ageing temperatures
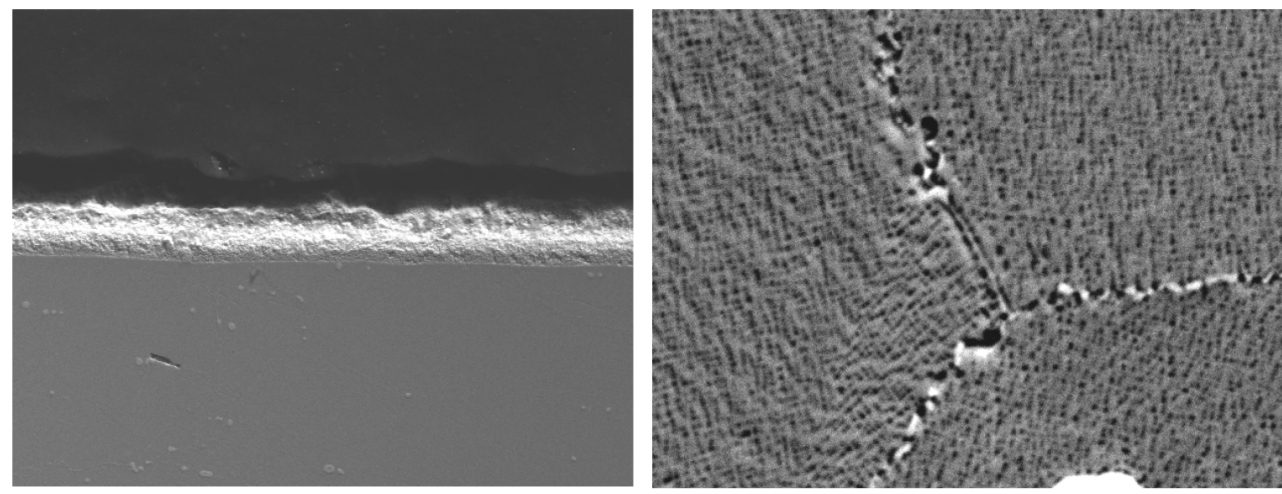

Fig. 12. The metallographic structure of a blade that has been aged at temperature of $1023 \mathrm{~K}$ during 1 h. a) coating (magn. x450); b) the surface-beneath layer (magn. $x 4500)$ 

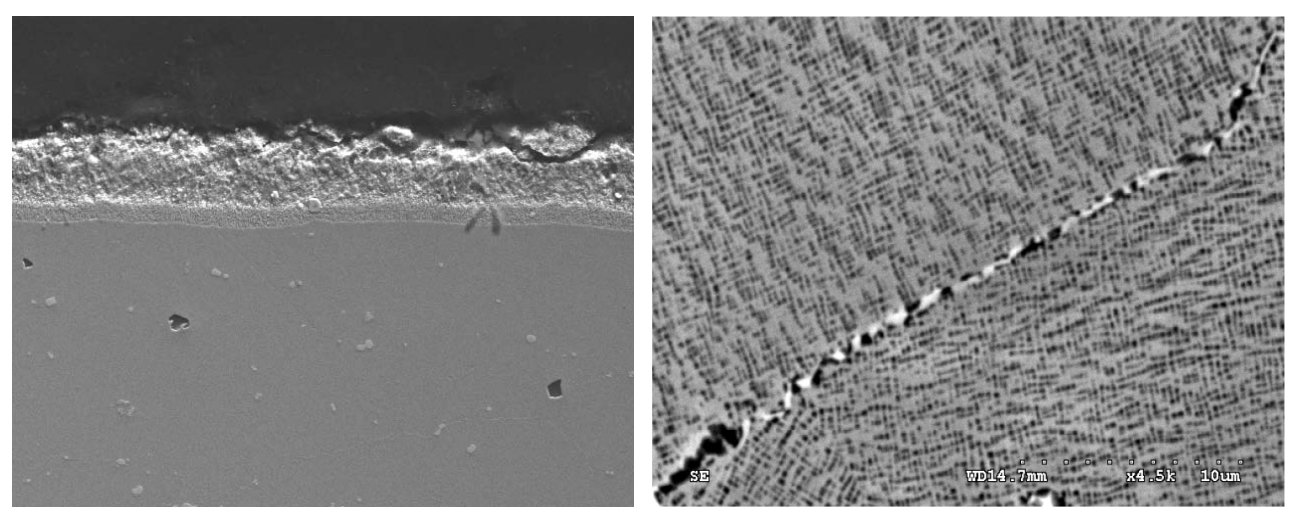

Fig. 13. The metallographic structure of a blade that has been aged at temperature of $1223 \mathrm{~K}$ during 1 h. a) coating (zoom x450); b) the surface-beneath layer (zoom $x 4500)$

When the material criterion is adopted, i.e. how the number of hits to the $\gamma$ ' phase has changed and it is the criterion that determines applicability of blades for further operation, one is able to determine a threshold limit for the blade lifetime. Results from metallographic tests confirm that the blade material loses its high-temperature creep resistance at the temperatures above $1223 \mathrm{~K}$ due to clustering of fine-grained (Fig. 12), cubical particles of the $\gamma$ ' phase and formation of plates (Fig. 13).Further examination included application of the thermographic method to exploration tests of vanes in those gas turbines that were in service concurrently to the examination time. The tests were focused on vanes made of the ŻS-6K alloy.

The analysis of results from examinations that have been carried out for vanes classified to $1^{\text {st }}$ and $5^{\text {th }}$ category of operability serve as a proof that the pulsed thermography is suitable to judge about material structure of turbine blades that are constantly in operation.

\section{Conclusions}

Operation of avionic turbine engines is associated with incidents when turbine blades are heated to temperatures that more or less exceed their regular working temperatures. For blades of gas turbines the deterioration process begins from destruction of their protective coatings with consequential exposure of the blade parent material to direct aggressive effect of exhaust gases. Such an effect results in overheating of the material, which is manifested by adverse alterations to the material infrastructure. 
It is why there is a need to use method so $\mathrm{n}$ on-destructive tests to much wider extent that was used to be done to date as these methods are particularly suitable to investigate overheating conditions of blades in turbines of avionic engines. In order to assess microstructure images of blades in gas turbines with higher accuracy, dependability and reliability, unreachable to the existing technologies, it is indispensable to develop fundamentals for a non-destructive test method that would be fast, direct and applicable to verification of the blade condition during maintenance or overhauls of engines. Initial investigations of gas turbine blades, carried out with use of the thermographic method for both brand new and already operated blades have demonstrated the relationships between the thermal loads during the blade service and variations in timings of thermal response associated with condition of the blade microstructure. These discovered relationships and associations shall serve as a basis to develop an innovative method for the non-destructive thermographic assessment of the overheating status attributable to the material of gas turbine blades.

\section{References:}

[1] Koizumi Y., Kobayashi T. et al.: Third generation single crystal superalloys with excellent processability and phase stability. Proc. of $6^{\text {th }}$ Liège conference, Part II, Belgium (1998), pp. 1089 - 1098.

[2] Lewitowicz J. [ed.] at al.: Fundamentals for operation of aircrafts. Vol. 4, Edition ITWL, Warsaw, 2007. (in Polish)

[3] Wiaterek R. et al: Rotating units of turbine engines. WKiŁ, Warszawa, 1982. (in Polish)

[4] Kułaszka, A. Szczepankowski A., Reports on research and development projects. ITWL, Warsaw 2000-2009 (not published). (in Polish)

[5] Błachnio, J.: The effect of high temperature on the degradation of heatresistant and high-temperature alloys. Solid State Phenomena, Vols. 147-149, 2009, pp. 744-752.

[6] Pawlak W. I. et al: Identification of the relationship between technical condition of turbojet engines and distribution of temperature fields upstream turbines. Report on the R\&D project KBN No 8T12D0142, Institute of Aviation, Warsaw, 2003. (in Polish)

[7] Błachnio J., Bogdan M.: Diagnostics of technical condition demonstrated by blades of gas turbines in service. Diagnostics. No 1 (45), 2008, pp. 91-96. (in Polish) 
[8] Błachnio J., Bogdan M.: A non-destructive method to assess a degree of overheating of gas turbine blades. Journal of Polish CIMAC, 2007, pp. 43-50.

[9] Bogdan M., Błachnio J.: Examinations on temperature distribution for driving units of aircrafts. Airplanes and helicopters diagnostics: AIRDIAG'2005: $8^{\text {th }}$ International Conference, Warsaw October 27-28, Conference proceedings, Ed. ITWL, Warsaw (2005), pp.31 - 38. (in Polish)

[10] Carl. V., Becker E., Sperling A.: Thermography inspection system for gas turbine blades. $7^{\text {th }}$ European Conference on non-destructive testing, Copenhagen pp. $2658-2665$.

(1998),

[11] Xavier P.V. Maldague, Theory and Practice of Infrared Technology for Nondestructive Testing, John Wiley, Interscience, New York, 2001.

[12] A. V. Luikov, Analytical Heat Diffusion Theory, Academic Press, New York and London, 1968.

[13] Oliferuk W.: Infrared thermography for non-destructive testing of materials and equipment. Gamma Office, Warsaw 2008. (in Polish)

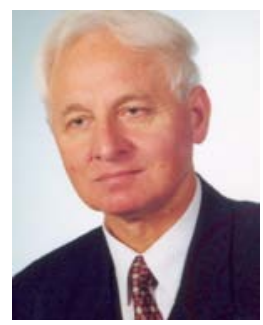

Józef Błachnio Prof. DSc. Eng. Air Force Institute of Technology Warsaw. Represented fields, disciplines, specialties of science: machine building and operation, materials engineering, technical diagnostics, airplanes, helicopters, aircraft engines. 